nised distilleries; in Russia the people still managed to make 183 million litres of alcohol at home. Despite widespread starvation and the sanction of severe punishment for moonshining, grain, sugar, and potatoes were turned into hooch.

As a second, contemporary, example to prove his point, Viktorov cites the experience of an unnamed city in the Russian Republic where the local administration ordered a reduction of $30 \%$ in the sale of alcoholic drinks. This policy was shown to be ineffectual when "speculation" in vodka started and the numbers of people taken into sobering up stations failed to decline. Moreover, Viktorov himself discovered that passengers in aircraft flying to that city from Moscow were helping to compensate for the local shortage by taking with them large quantities of "alcoholic souvenirs."

\section{Enlightened strategies}

By contrast, the city of Naberezhniye Chelni has adopted a far more advanced approach, which implicitly recognises the importance of a range of social and cultural factors. It was there during the 1970s that a giant complex (the Kama Automobile Works) was constructed to manufacture heavy trucks and engines, and at the start the city imposed a "strict limitation" on the sale of alcoholic drinks. The consequence was that "speculation" in vodka started up. Local organs of the party and its auxiliary the Young Communist League (Komsomol), however, responded by evolving a set of measures mainly directed at fostering a more sensible and creative use of leisure time. With the subsequent development of cultural and recreational facilities, the city's reported crime rate-a key indicator of social pathology-became one of the lowest for urban areas in the Soviet Union.

In 1977 the city's decision to lift restrictions on the sale of alcohol was regarded initially with considerable misgiving, especially since the average age of the population was only 25 . Public organisations, however, had drawn up plans to take account of this policy change. A commission for combating drunkenness and alcoholism was set up, and each year it formulates a set of measures to improve the prevention of crime, particularly crime arising from drunkenness. The main thrust of the strategy is not so much towards the analysis of incidents caused by drunks as towards "the problem of spare time, recreation, and the organisation of courses about the law for both the adult and teenage population."

Statistics quoted by Viktorov indicate some of the improvements achieved in facilities that are obviously intended as alternative attractions to drinking. In 1977 the city (whose population is around 346000 ) had 75 libraries; by 1980 the figure had risen to 105 , and the stock of books had nearly doubled. Over the same period, amateur art groups rose from 445 to 580 . In the 121 hostels, which accommodate some 50000 young people, a total of 145 lecture courses and 86 hobby clubs are now operating.
As a result of these developments, it is thought, indicators of personal disaffection and frustration are registering a decline. Thus during 1979 to 1980 the amount of working time lost in the city's industry fell by $19 \%$, absenteeism by $8 \%$, andprobably just as welcome-the number of crimes committed under the influence of drink fell by $11 \%$. Consumption of alcohol, which had started to rise, has now fallen back and hardened drinkers are turning to grape wines.

\section{Involvement of doctors}

Another success story is reported from Kursk (also located in the Russian Republic). There the regional Soviet established a preventive centre whose functions include research, organisation of "raids," public education programmes, and work with individuals. The activity of this centre is supervised by the department of psychotherapy at Kursk medical institute, a point of detail worth noting since the overall responsibility for antialcohol campaigns rests not with the Health Ministry but with a law and order agency, the Ministry of Internal Affairs. When Viktorov wrote his article, a mere seven months had elapsed since the inception of this centre, but already the number of street crimes committed in the city had declined considerably.

Viktorov's third example of pioneering work with a positive outcome relates to an experimental prophylactorium (as it is termed) at a factory in Dmitrov, not far from Moscow. The regimen of treatment there consists of three elements: "reflexotherapy," with ethyl chloride, sessions with a psychiatrist, and, finally, what seems to be a form of social work involving members of the patient's family and companions at work. Despite a heavy case load, this prophylactorium is evidently achieving satisfactory results. "Former patients," Viktorov reports, "have turned into ordinary workers. Peace and tranquillity reign in their families. The 'sobering up' of parents has been seen in the progress and behaviour of their children at school." As for the success rate, the local Ministry of Internal. Affairs office provided statistics showing that 207 alcoholics had begun treatment in the unit during the past three years and that 111 of them no longer required continuous supervision.

Viktorov's basic message can hardly be misunderstood: the problem of heavy drinking requires carefully designed and well executed programmes, not grand gestures arising from moral indignation. And as a final example of the wrong approach, he cites Dudochkin's proposal for "a special antialcohol censorship" of books, films, and plays. One can only speculate whether that notion would entail the appointment of some latter day Thomas Bowdler to abbreviate well loved lines by Pushkin and to excise pages from the masterpieces of Tolstoy.

\section{Reference}

1 Viktorov D. Na trezvuyu golovu. Literaturnaya Gazeta 1982;31:12.
An asthmatic patient suffers from excess sweating. During a recent short course of steroids for an exacerbation of his asthma, he noticed that his sweating was reduced. Since reducing the dose of steroids his sweating has now returned. Is this to be expected, and what is the explanation?

Most therapeutic corticosteroid analogues have some effect in retaining sodium, and thus water, so that reduced sweating may occur, at least temporarily. This effect is rarely noticed by patients but seems the likely explanation in the case cited. There is no evidence that asthma is a deficiency disease because of hypofunction of the adrenal glands. In patients dying from asthma who have had prolonged treatment with corticosteroids before death evidence of adrenal hypofunction is often found, but in patients who have died from asthma without having had corticosteroid treatment, except perhaps for a short period in the terminal illness, there may be evidence of increased adrenocortical activity. Plasma cortisol values before death in such cases may be considerably raised owing to stress in the course of status asthmaticus.- JOHN MORRISON SMITH, honorary consultant physician, Birmingham

\section{Correction}

\section{Ward meetings: a forum for patients' concerns}

We regret that an error appeared in the paper by Dr J Graffy (29 January, p 371). The last sentence of the paragraph on ward meetings should have read "Though very ill patients were inevitably underrepresented, two thirds of inpatients did attend, which suggests that the meetings were representative." 